CLINICAL STUDY

\title{
A meta-analysis of the associations between common variation in the PDESB gene and thyroid hormone parameters, including assessment of longitudinal stability of associations over time and effect of thyroid hormone replacement
}

\author{
Peter N Taylor ${ }^{1}$, Vijay Panicker ${ }^{1,2}$, Adrian Sayers ${ }^{3}$, Beverley Shields ${ }^{4}$, Ahmed Iqbal $^{1}$, Alexandra P Bremner ${ }^{5}$, \\ John P Beilby ${ }^{6}$, Peter J Leedman ${ }^{2,7,8}$, Andrew T Hattersley ${ }^{4}$, Bijay Vaidya ${ }^{9}$, Timothy Frayling ${ }^{4}$, Jonathan Evans ${ }^{10}$, \\ Jonathan H Tobias ${ }^{3}$, Nicholas J Timpson ${ }^{11}$, John P Walsh ${ }^{2,12}$ and Colin M Dayan ${ }^{1,13}$ \\ ${ }^{1}$ Henry Wellcome Laboratories for Integrative Neurosciences and Endocrinology, University of Bristol, Bristol BS1 3NY, UK, ${ }^{2}$ School of Medicine \\ and Pharmacology, University of Western Australia, Crawley, Western Australia 6009, Australia, ${ }^{3}$ Academic Rheumatology, Avon Orthopaedic Centre, \\ Southmead Hospital, Bristol BS1O 5NB, UK, ${ }^{4}$ Peninsula NIHR Clinical Research Facility, Peninsula Medical School, University of Exeter, Exeter \\ PL6 8BU, UK, ${ }^{5}$ School of Population Health, University of Western Australia, Crawley, Western Australia 6009, Australia, ${ }^{6}$ Pathwest Laboratory \\ Medicine, WA, Nedlands, Western Australia 6009, Australia, ${ }^{7}$ Laboratory for Cancer Medicine, Western Australian Institute for Medical Research, Centre \\ for Medical Research, University of Western Australia, Perth, Western Australia 6000, Australia, ${ }^{8}$ Department of Endocrinology and Diabetes, Royal Perth \\ Hospital, Perth, Western Australia 6847, Australia, ${ }^{9}$ Department of Endocrinology, Royal Devon and Exeter Hospital, Exeter EX2 5DW, UK, ${ }^{10}$ Academic \\ Unit of Psychiatry University of Bristol, Bristol BS6 6JL, UK, ${ }^{11}$ Department of Social Medicine, MRC Centre for Causal Analyses in Translational \\ Epidemiology, University of Bristol, Bristol BS8 2BN, UK, ${ }^{12}$ Department of Endocrinology and Diabetes, Sir Charles Gairdner Hospital, Nedlands, Western \\ Australia 6009, Australia and ${ }^{13}$ Cardiff University School of Medicine, Centre for Endocrine and Diabetes Science, Heath Park, Cardiff CF14 4XN, \\ Wales, UK \\ (Correspondence should be addressed to C M Dayan at Cardiff University School of Medicine; Email: dayancm@cardiff.ac.uk)
}

\begin{abstract}
Objective: Common variants in PDE8B are associated with TSH but apparently without any effect on thyroid hormone levels that is difficult to explain. Furthermore, the stability of the association has not been examined in longitudinal studies or in patients on levothyroxine $\left(\mathrm{L}-\mathrm{T}_{4}\right)$.

Design: Totally, four cohorts were used $(n=2557)$ : the Busselton Health Study (thyroid function measured on two occasions), DEPTH, EFSOCH (selective cohorts), and WATTS (individuals on L-T 4 ). Methods: Meta-analysis to clarify associations between the rs4704397 single nucleotide polymorphism in PDE 8B on TSH, tri-iodothyronine $\left(\mathrm{T}_{3}\right)$, and $\mathrm{T}_{4}$ levels.

Results: Meta-analysis confirmed that genetic variation in PDE8B was associated with TSH $\left(P=1.64 \times 10^{-10} 0.20\right.$ s.D./allele, 95\% confidence interval $\left.(C I) 0.142,0.267\right)$ and identified a possible new association with free $\mathrm{T}_{4}(P=0.023,-0.07$ s.D./allele, 95\% CI $-0.137,-0.01)$, no association was seen with free $\mathrm{T}_{3}(P=0.218)$. The association between PDE $8 B$ and TSH was similar in 1981 (0.14 s.D./allele, 95\% CI 0.04, 0.238) and 1994 (0.20 s.D./allele, 95\% CI 0.102, 0.300) and even more consistent between PDE8B and free $\mathrm{T}_{4}$ in 1981 ( -0.068 s.D./allele, 95\% CI $\left.-0.167,0.031\right)$ and 1994 ( -0.07 s.D./allele, 95\% CI -0.170, 0.030). No associations were seen between PDE8B and thyroid hormone parameters in individuals on $\mathrm{L}-\mathrm{T}_{4}$.

Conclusion: Common genetic variation in PDE8B is associated with reciprocal changes in TSH and free $\mathrm{T}_{4}$ levels that are consistent over time and lost in individuals on $\mathrm{L}_{-} \mathrm{T}_{4}$. These findings identify a possible genetic marker reflecting variation in thyroid hormone output that will be of value in epidemiological studies and provides additional evidence that PDE8B is involved in TSH signaling in the thyroid.
\end{abstract}

European Journal of Endocrinology 164 773-780

\section{Introduction}

Variation in thyroid function within the reference range is associated with important differences in key biological outcomes in the general population. These include body mass index, lipid levels, blood pressure, childhood development, and risk of fatal ischemic heart disease events (1-5). Although nominally informative, these studies have all relied upon measurements of serum thyroid hormone levels taken on a single occasion. This approach may not represent an individual's lifetime exposure and is also susceptible to confounding factors $(6,7)$. For example, cigarette smoking is associated with reduced TSH concentrations, (8) making it difficult to accurately assess the effect of thyroid dysfunction on cardiovascular disease (5).

Genetic association studies represent an alternative method to study life course differences in the thyroid commercial use, distribution, and reproduction in any medium, provided the original work is properly cited. 
hormone pathway and phenotypic outcomes. The genetic approach avoids confounding and reverse causation effects present in traditional epidemiological studies. It may also better reflect lifetime exposure to thyroid hormones than a single serum measurement. For the genetic approach to be practical, robust genetic associations with thyroid hormone levels need to be established.

At present, the genetic and temporal architecture of this important trait remains incompletely understood. Genomewide association studies (GWAS) and candidate gene studies have identified single nucleotide polymorphisms (SNPs) in a number of genes that have been associated with variance in TSH levels or the free thyroxine $\left(\mathrm{T}_{4}\right)$ /free tri-iodothyronine $\left(\mathrm{T}_{3}\right)$ ratio in the normal population (9-11). However, to date, no genetic variant has been confirmed at a high level of statistical significance to be associated with the overall thyroid function set point. Furthermore, no data exist on the temporal stability of genetic associations with thyroid function over time. Both these elements are key in determining whether a genetic marker can be found that is a valuable surrogate for lifetime thyroid hormone exposure.

Arnaud-Lopez et al. (10) identified that variation in rs4704397 SNP in PDE8B was associated with altered TSH levels in the reference range. This initial study, however, did not include free $\mathrm{T}_{3}$ and free $\mathrm{T}_{4}$ levels. As PDE $8 B$ encodes a cAMP phosphodiesterase enzyme (12), strongly expressed in the thyroid gland (13-15) but undetectable in the pituitary gland (16), it was postulated that its influence on thyroid hormone parameters was via the hydrolysis and inactivation of cAMP in the thyroid in response to TSH signaling. This work raises the possibility that variation in PDE $8 B$ influences the thyroid hormone set point by making the thyroid less responsive to TSH, equivalent to a mild degree of thyroid failure resulting in higher TSH levels. Such a mode of action would be expected to also result in changes in thyroid hormone levels, in a reciprocal direction to the change in TSH.

Intriguingly, a recent study of 1017 pregnant women (17) replicated the association of this SNP with TSH levels but failed to find any evidence of association with free $\mathrm{T}_{3}$ and free $\mathrm{T}_{4}$ levels. However, due to the log-linear relationship between TSH and thyroid hormone levels, small changes in thyroid hormone levels result in relatively large changes in TSH; this study might, therefore, have been underpowered to detect associations between PDE $8 B$ and free $\mathrm{T}_{3}$ and free $\mathrm{T}_{4}$ levels.

In this study, we undertook a meta-analysis to investigate the association between variation at rs4704397 SNP in PDE8B on free $\mathrm{T}_{3}$ and free $\mathrm{T}_{4}$ levels in the general population and in individuals on thyroid hormone replacement and assessed the temporal stability of its effects in the Busselton cohort (18). As a control, we also studied the temporal stability of the rs2235544 SNP in the deiodinase 1 (DIO1) gene which our group previously identified was associated with altered free $\mathrm{T}_{3} /$ free $\mathrm{T}_{4}$ ratio $\left(P=3.6 \times 10^{-13}\right.$ effect size 0.2 s.D./allele s.E.M. 0.003) and altered free $\mathrm{T}_{4}$ levels $\left(P=2.1 \times 10^{-9}\right)$ but not serum TSH levels (11). Furthermore, we aimed to test whether variation in PDE $8 B$ was still associated with TSH in individuals on $\mathrm{L}^{-} \mathrm{T}_{4}$.

Finally, we also explored two new candidate SNPs, rs10499559 in RAPGEF5 and rs9322817 in HACE1. These two SNPs had the strongest associations with TSH $\left(P=8.3 \times 10^{-6}\right.$ and $6.5 \times 10^{-6}$ respectively $)$ where the identity of the gene tagged by the SNP was defined (19) using generalized estimating equations (GEE), from a GWAS of the Framingham Heart Study. The GEE analysis from this study was utilized as it estimates the average response over a population, rather than familial aggregation and hereditability. Therefore, SNPs identified with the GEE approach would be potentially very applicable for use in Mendelian Randomization studies in epidemiological cohorts.

Although these SNPs could have been identified due to a type 1 error, RAPGEF5 is a member of the RAS subfamily of GTPases and is the key link between cell surface receptors and RAS activation. It is expressed in a wide variety of tissues including the thyroid, and we postulated that it may also be involved in TSH signaling. HACE1 is expressed in multiple tissues including the heart, brain, and kidney but is not thought to be present in the thyroid gland. We postulated that its association with TSH may be due to differences in detection of thyroid hormone in the brain.

\section{Subjects and methods}

In this study, four cohorts were used: the Busselton Health Study (Busselton), the Depression and Thyroid Disease study (DEPTH), The Exeter Family Study of Childhood Health (EFSOCH), and The Weston Area $\mathrm{T}_{3} \mathrm{~T}_{4}$ Study (WATTS). These studies have all been described previously $(11,20-22)$. Busselton is a community-based cohort in which individuals were tested for thyroid function on two occasions 13 years apart (1981 and 1994), DEPTH is a primary care cohort of individuals referred for thyroid function testing, EFSOCH is a cohort of male partners of pregnant women recruited for a family study, and WATTS is a cohort of patients on thyroid hormone replacement recruited for an intervention study. Baseline characteristics of all cohorts are presented in Table 1. Further details of the cohorts/ collections can be found in the Supplementary data, see section on supplementary data given at the end of this article. All individuals in all cohorts were of white European ancestry.

To examine the association of genetic variation with endogenous thyroid hormone levels separately from the effects of disease processes or medication that affects thyroid function, individuals with any $\mathrm{TSH}$, free $\mathrm{T}_{3}$, or 
Table 1 Baseline characteristics of the cohorts (S.D. in brackets).

\begin{tabular}{llllll}
\hline Characteristic & Busselton & DEPTH & WATTS & $\begin{array}{l}\text { WATTS abnormal } \\
\text { TSH removed }\end{array}$ & EFSOCH \\
\hline$n$ & 825 & 387 & 544 & 387 & 801 \\
$\%$ Male & 50.1 & 22.7 & 16.5 & 14.5 & 100 \\
Age (years) & $45.1( \pm 14.2)$ & $43.6( \pm 14.7)$ & $57.0( \pm 11.1)$ & 55.6 & $32.7( \pm 5.9)$ \\
TSH (mU/l) & 1.47 & 1.72 & 1.47 & 1.61 & 1.99 \\
Free T $_{3}(\mathrm{pmol} / \mathrm{l})$ & $5.53( \pm 0.53)$ & $4.67( \pm 0.63)$ & $3.84( \pm 0.72)$ & $3.78( \pm 0.69)$ & $5.51( \pm 0.53)$ \\
Free T $_{4}(\mathrm{pmol} / \mathrm{l})$ & $16.6( \pm 2.64)$ & $16.3( \pm 2.65)$ & $21.1( \pm 3.68)$ & $20.3( \pm 3.23)$ & $16.5( \pm 2.02)$ \\
\hline
\end{tabular}

free $\mathrm{T}_{4}$ levels outside the reference ranges for the assays used (see Supplementary data) were excluded from the Busselton, DEPTH, and EFSOCH cohorts. These exclusions were not applied to the WATTS cohort in which subjects were on thyroid hormone replacement and WATTS was, therefore, excluded from the metaanalysis of the cohorts. Subgroup analysis was subsequently performed for the WATTS-cohort individuals with $\mathrm{TSH}$, free $\mathrm{T}_{3}$, or free $\mathrm{T}_{4}$ levels outside the reference range excluded.

\section{Statistical analyses}

Descriptive statistics of the three cohorts are presented as means and S.D. TSH results across the cohorts were not normally distributed; a $\log _{\mathrm{e}}$ transformation was, therefore, used to normalize the data.

Within each cohort, the association per minor allele of the different genotypes and serological markers was assessed using ordinary least squares (OLS) linear regression. Results are presented in both 'natural' and 'standardized' (per s.D.) units; all models were adjusted for age and sex. Simple inverse variance weighted (fixed effects) meta-analysis was performed to pool study specific results and combined estimates and $P$ values presented along with metrics of heterogeneity. Additional individual patient data (IPD) meta-analysis was performed on genetic markers shown to be associated with serological markers (i.e. $P<0.05$ ).
The IPD meta-analysis was performed with a multilevel regression model using restricted maximum likelihood estimation; cohort was entered as a random effect to preserve the hierarchical nature of the data. IPD meta-analysis models were successively adjusted for sex, age, free $\mathrm{T}_{3}$, and free $\mathrm{T}_{4}$. We tested for heterogeneity using the $Q$ statistics.

To assess the temporal stability of the genetic effect, the Busselton cohort was studied using a series of multivariate seemingly unrelated regression (SUR) models. SUR is a generalization of OLS linear regression, which allows simultaneous model fitting between two different outcomes (serological levels in 1981 and 1994), and a consistent genetic exposure. The SUR enables the genetic effect between 1981 and 1994 to be tested and the residual (error) correlation between 1981 and 1994 to be explored.

All data analysis was performed using STATA version 11.0 (STATACORP, College Station, TX, USA).

\section{Results}

\section{Study populations}

Circulating levels of free $\mathrm{T}_{3}$ and free $\mathrm{T}_{4}$ were approximately normally distributed in the Busselton, DEPTH, EFSOCH, and WATTS cohorts. Log transformation of TSH led to a near-normal distribution. Table 2

Table 2 Genotype frequencies and Hardy-Weinburg equilibrium $\left(\chi^{2}\right)$ by cohort.

\begin{tabular}{|c|c|c|c|c|c|c|c|c|c|c|}
\hline \multirow[b]{2}{*}{ Gene SNP } & \multirow[b]{2}{*}{ Cohort } & \multicolumn{7}{|c|}{ Genotype and frequency (\%) } & \multirow[b]{2}{*}{ Total } & \multirow[b]{2}{*}{$\chi^{2}$} \\
\hline & & $A: A$ & $A: G$ & G:G & $A: C$ & C:C & C:T & $\mathrm{T}: \mathrm{T}$ & & \\
\hline \multirow[t]{4}{*}{ PDE8B (rs4704397) } & Busselton & $116(14.1)$ & $397(45.2)$ & $317(38.4)$ & & & & & 825 & 0.07 \\
\hline & DEPTH & $66(17.1)$ & 201 (51.9) & $120(31.1)$ & & & & & 387 & 1.36 \\
\hline & WATTS & $87(16.9)$ & $243(41.2)$ & $185(35.9)$ & & & & & 515 & 0.22 \\
\hline & EFSOCH & $131(16.35)$ & $374(46.7)$ & $296(37.0)$ & & & & & 801 & 0.05 \\
\hline DIO1 (rs223554) & DEPTH & $103(27.2)$ & & & $176(46.8)$ & $98(25.9)$ & & & 377 & 1.65 \\
\hline \multirow[t]{3}{*}{ RAPGEF5 (rs10499559) } & Busselton & & & & & $623(75.3)$ & $187(23.0)$ & $20(2.4)$ & 827 & 1.73 \\
\hline & DEPTH & & & & & $284(77.7)$ & $74(20.1)$ & $10(2.72)$ & 368 & 3.5 \\
\hline & WATTS & & & & & $400(82.1)$ & $72(14.7)$ & $15(3.1)$ & 487 & 21.8 \\
\hline \multirow[t]{3}{*}{ HACE1 (rs9322817) } & Busselton & $312(37.8)$ & & & $390(47.2)$ & $123(14.9)$ & & & 825 & 0 \\
\hline & DEPTH & $145(41.2)$ & & & $157(44.6)$ & $50(14.2)$ & & & 352 & 1.6 \\
\hline & WATTS & $171(38.7)$ & & & $195(44.2)$ & 75 (17.1) & & & 441 & 2.26 \\
\hline
\end{tabular}

${ }^{\text {a } I n c i d e n c e s ~ o f ~ t h e ~ r s 2235544 ~(D I O 1) ~ g e n o t y p e s ~ i n ~ t h e ~ W A T T S ~ c o h o r t ~ h a s ~ b e e n ~ p u b l i s h e d ~ p r e v i o u s l y ~(11) . ~}$ 
demonstrates that all SNPs were in Hardy-Weinberg equilibrium (HWE) in all cohorts except for rs10499559 in RAPGEF5 in the WATTS cohort. There were difficulties in genotyping this SNP from the DNA stores available, and this led to an unusually high error rate; furthermore, there were difficulties in distinguishing between the $\mathrm{CC}$ and the CT genotype. We have presented the data for this SNP in WATTS, but it should be interpreted with caution.

\section{Effects on TSH and serum thyroid hormone levels in individuals with intact thyroid function}

The meta-analysis of three cohorts of individuals not on thyroid hormone replacement reconfirmed the association between the rs4704397 SNP in the PDE8B on TSH levels $\left(P=1.64 \times 10^{-10}\right)$. Table 3 shows results for the individual cohorts, and the results of the metaanalysis are shown in Table 4. Minimal attenuation of the effect was observed (see Fig. 1) after adjusting for multiple covariates including free $\mathrm{T}_{4}$, and only a small increase in the s.E.M. was observed, resulting in a small increase in the $P$ value from $P=2.95 \times 10^{-10}$ (unadjusted) to $P=1.64 \times 10^{-10}$ (fully adjusted). Meta-analysis also revealed an association with free $\mathrm{T}_{4}$ levels $(P=0.023)$, in the opposite direction to the association seen with TSH.

Our meta-analysis also validated the association with the rs223554 SNP in the DIO1 gene on free $\mathrm{T}_{4}$ $(P=0.001)$ and free $\mathrm{T}_{3} /$ free $\mathrm{T}_{4}$ ratio $\left(P=9.26 \times 10^{-4}\right)$ and confirmed that there was no association with TSH $(P=0.32)$.

\section{The effect of variation in the PDESB and DIO1 genes on serum thyroid hormone and TSH levels over time in the same individuals in the Busselton cohort}

In the Busselton cohort, the effect size per minor A allele of the rs4704397 SNP of the PDE $8 B$ gene on TSH levels in 1981 was 0.141 s.D./allele $(P=0.005$ (95\% confidence interval (CI) $0.04,0.24)$ ), and on repeat testing in 1994 , there was no evidence for difference in effect estimate at 0.189 s.D./allele $(P=0.0001$ (95\% CI 0.09, $0.28)$ ). There was also a similar effect size per minor $\mathrm{A}$ allele on free $\mathrm{T}_{4}$ in 1981 of -0.068 s.D./allele (95\% CI $-0.167,0.031)$ ) and in $1994-0.07$ s.D./allele $(95 \%$ CI $-0.170,0.030))$. Testing the difference in genetic effects for PDE8B on TSH between 1981 and 1994 showed that there was no evidence of any difference $(P=0.32)$. The residual error correlation between 1981 and 1994 was also very high $(r=0.5467, P=0.0001)$, again indicating commonality of effect.

Very similar results were obtained for the effect size per minor $\mathrm{C}$ allele of the rs2235544 SNP of the DIO1 gene on $\mathrm{T}_{4}$ levels in 1981: -0.136 s.D./allele $(P=0.0054(95 \%$ CI $-0.23,-0.042))$ versus 0.131
S.D./allele $(P=0.00695 \%$ CI $-0.225,-0.037)$ in 1994. Testing the difference in genetic effects between 1981 and 1994 showed that there was no evidence of any difference $(P=0.93)$ and the residual error correlation between 1981 and 1994 was also high $(r=0.368)$, again indicating commonality of effect.

\section{The associations between PDESB and thyroid hormone parameters on TSH in individuals on thyroid hormone replacement}

The WATTS cohort (individuals on thyroid hormone replacement) was analyzed separately. In this cohort, unlike the general population, we observed no evidence of association with the rs4704397 SNP in the PDE8B gene on TSH levels $(P=0.99)$. Similarly, no effect of this PDE 8B SNP was seen on free $\mathrm{T}_{4}(P=0.59)$ or free $\mathrm{T}_{3}$ levels $(P=0.90)$. By contrast, an effect was seen on free $\mathrm{T}_{4} /$ free $\mathrm{T}_{3}$ ratio with the DIO1 SNP in this cohort as previously reported (11).

Our meta-analysis failed to confirm any association between genetic variation in rs10499559 in RAPGEF5 on $\mathrm{TSH}(P=0.67)$, free $\mathrm{T}_{3}(P=0.21)$, or free $\mathrm{T}_{4}$ $(P=0.49)$. Our meta-analysis also found no evidence of association between genetic variation in rs9322817 in HACE1 on TSH $(P=0.93)$, free $\mathrm{T}_{3}(P=0.94)$, or free $\mathrm{T}_{4}(P=0.09)$.

\section{Discussion}

Our meta-analysis has confirmed that the rs4704397 SNP in the PDE8B gene is associated with variation in TSH levels, in keeping with the initial report of ArnaudLopez et al. (10) and a subsequent study in pregnant women (20). However, the additional power available to us in this meta-analysis enabled us to detect that this SNP is also reciprocally associated with free $\mathrm{T}_{4}$ levels. For each additional minor A allele at this SNP, there was an increase in TSH levels and a reduction in free $\mathrm{T}_{4}$ levels, indicating relative hypothyroidism (Fig. 1). Although the level of significance for the association with free $\mathrm{T}_{4}$ remains modest, and further larger confirmatory studies are required to validate this, our finding is supported by its replication in the same individuals 13 years later in the Busselton cohort. Associations with the rs2235544 SNP in DIO1 were also consistent over time, but by contrast, this SNP was associated with free $\mathrm{T}_{4}$ /free $\mathrm{T}_{3}$ ratio and not TSH (11). We found no evidence of association between SNPs, rs10499559 in RAPGEF5 gene and rs9322817 in HACE1 gene, on thyroid hormone parameters.

These findings are important for two reasons. First, they potentially resolve the paradox raised by Shields et al. (17), which demonstrated an association with the rs4704397 SNP of PDE8B on TSH, but no evidence of association with free $\mathrm{T}_{3}$ or $\mathrm{T}_{4}$. Therefore, we have provided evidence that this SNP is a valuable marker for 
Table 3 The effect of variation in rs4704397 in PDE8B, rs223554 in DIO1, rs10499559 in RAPGEF5, and rs9322817 in HACE1 on TSH and serum thyroid hormone levels by cohort.

\begin{tabular}{|c|c|c|c|c|c|c|}
\hline & \multirow[b]{2}{*}{$n$} & \multicolumn{2}{|c|}{$\beta$ estimate } & \multirow[b]{2}{*}{ Std. $95 \%$ Cl } & \multirow[b]{2}{*}{$P$} & \multirow[b]{2}{*}{$r^{2}$} \\
\hline & & Natural & Std. & & & \\
\hline \multicolumn{7}{|l|}{$\begin{array}{l}\text { TSH } \\
P D F R B\end{array}$} \\
\hline Busselton 1981 & 825 & 0.066 & 0.139 & 0.040 to 0.238 & 0.0062 & 0.011 \\
\hline Busselton 1994 & 825 & 0.095 & 0.201 & 0.102 to 0.300 & 0.0001 & 0.031 \\
\hline DEPTH & 387 & 0.122 & 0.225 & 0.079 to 0.371 & 0.0026 & 0.025 \\
\hline WATTS & 515 & 0 & 0 & -0.123 to 0.122 & 0.9970 & 0.001 \\
\hline $\mathrm{EFSOCH}$ & 801 & 0.096 & 0.199 & 0.101 to 0.297 & 0.0001 & 0.02 \\
\hline \multicolumn{7}{|l|}{ DIO1 } \\
\hline Busselton 1981 & 822 & 0.029 & 0.06 & -0.035 to 0.155 & 0.2160 & 0.004 \\
\hline Busselton 1994 & 818 & 0.001 & 0.001 & -0.093 to 0.096 & 0.9770 & 0.012 \\
\hline DEPTH & 377 & -0.068 & -0.125 & -0.262 to 0.013 & 0.0760 & 0.012 \\
\hline \multicolumn{7}{|l|}{ RAPGEF5 } \\
\hline Busselton 1981 & 827 & 0.017 & 0.037 & -0.104 to 0.177 & 0.6098 & 0.002 \\
\hline Busselton 1994 & 822 & -0.016 & -0.033 & -0.173 to 0.107 & 0.6453 & 0.012 \\
\hline DEPTH & 368 & -0.005 & -0.009 & -0.217 to 0.199 & 0.9302 & 0.002 \\
\hline WATTS & 487 & -0.165 & -0.104 & -0.291 to 0.083 & 0.2779 & 0.006 \\
\hline \multicolumn{7}{|l|}{ HACE1 } \\
\hline Busselton 1981 & 825 & 0.034 & 0.072 & -0.027 to 0.171 & 0.1527 & 0.005 \\
\hline Busselton 1994 & 821 & 0.008 & 0.017 & -0.082 to 0.116 & 0.7333 & 0.012 \\
\hline DEPTH & 352 & -0.028 & -0.052 & -0.203 to 0.098 & 0.4950 & 0.002 \\
\hline WATTS & 441 & -0.022 & -0.014 & -0.147 to 0.12 & 0.8405 & 0.002 \\
\hline \multicolumn{7}{|l|}{$\begin{array}{c}\text { Free } \mathrm{T}_{3}{ }^{\mathbf{a}} \\
P D E 8 B\end{array}$} \\
\hline Busselton 1994 & 825 & -0.034 & -0.048 & -0.147 to 0.050 & 0.3343 & 0.04 \\
\hline DEPTH & 387 & -0.03 & -0.048 & -0.195 to 0.100 & 0.5271 & 0.001 \\
\hline WATTS & 515 & 0.006 & 0.008 & -0.116 to 0.133 & 0.8955 & 0.004 \\
\hline $\mathrm{EFSOCH}$ & 801 & -0.014 & -0.027 & -0.123 to 0.070 & 0.5859 & 0.053 \\
\hline \multicolumn{7}{|l|}{ DIO1 } \\
\hline Busselton 1994 & 818 & 0.066 & 0.094 & 0.000 to 0.187 & 0.0492 & 0.043 \\
\hline DEPTH & 377 & 0.003 & 0.005 & -0.133 to 0.144 & 0.9399 & 0 \\
\hline \multicolumn{7}{|l|}{ RAPGEF5 } \\
\hline Busselton 1994 & 822 & -0.063 & -0.089 & -0.227 to 0.049 & 0.2054 & 0.04 \\
\hline DEPTH & 368 & -0.024 & -0.038 & -0.247 to 0.171 & 0.7242 & 0.001 \\
\hline \multirow{2}{*}{\multicolumn{7}{|c|}{ HACE1 }} \\
\hline & & & & & & \\
\hline Busselton 1994 & 821 & -0.012 & -0.017 & -0.115 to 0.081 & 0.7352 & 0.039 \\
\hline DEPTH & 352 & 0.018 & 0.029 & -0.122 to 0.179 & 0.7111 & 0.001 \\
\hline WATTS & 441 & 0.08 & 0.11 & -0.023 to 0.243 & 0.1058 & 0.007 \\
\hline \multirow{2}{*}{\multicolumn{7}{|c|}{$\begin{array}{c}\text { Free } \mathbf{T}_{\mathbf{4}} \\
P D E 8 B\end{array}$}} \\
\hline & & & & & & \\
\hline Busselton 1981 & 825 & -0.179 & -0.068 & -0.167 to 0.031 & 0.1791 & 0.029 \\
\hline Busselton 1994 & 825 & -0.186 & -0.07 & -0.170 to 0.030 & 0.1696 & 0.003 \\
\hline DEPTH & 387 & -0.276 & -0.104 & -0.251 to 0.043 & 0.1665 & 0.006 \\
\hline WATTS & 515 & 0.126 & 0.034 & -0.090 to 0.158 & 0.5897 & 0.001 \\
\hline $\mathrm{EFSOCH}$ & 801 & -0.13 & -0.064 & -0.163 to 0.035 & 0.2032 & 0.002 \\
\hline \multicolumn{7}{|l|}{ DIO1 } \\
\hline Busselton 1981 & 822 & -0.35 & -0.133 & -0.226 to -0.040 & 0.0052 & 0.035 \\
\hline Busselton 1994 & 818 & -0.341 & -0.129 & -0.224 to -0.034 & 0.0079 & 0.01 \\
\hline \multicolumn{7}{|l|}{ RAPGEF5 } \\
\hline Busselton 1981 & 827 & 0.119 & 0.045 & -0.093 to 0.184 & 0.5219 & 0.026 \\
\hline Busselton 1994 & 822 & -0.05 & -0.019 & -0.160 to 0.122 & 0.7924 & 0.001 \\
\hline DEPTH & 368 & -0.239 & -0.09 & -0.300 to 0.119 & 0.3989 & 0.002 \\
\hline WATTS & 487 & 0.055 & 0.015 & -0.171 to 0.201 & 0.8751 & 0.001 \\
\hline \multicolumn{7}{|l|}{ HACE1 } \\
\hline Busselton 1981 & 825 & -0.048 & -0.018 & -0.116 to 0.079 & 0.7160 & 0.027 \\
\hline Busselton 1994 & 821 & -0.102 & -0.039 & -0.138 to 0.061 & 0.4471 & 0.002 \\
\hline DEPTH & 352 & -0.387 & -0.146 & -0.293 to 0.001 & 0.0524 & 0.016 \\
\hline WATTS & 441 & -0.045 & -0.012 & -0.142 to 0.118 & 0.8544 & 0 \\
\hline
\end{tabular}

Std., standardized.

Std., standardized.
${ }^{a}$ Free $T_{3}$ levels not available in the Busselton 1981 data set. 
Table 4 Meta-analysis to show associations between variation in rs4704397 in PDE8B, rs223554 in DIO1, rs10499559 in RAPGEF5, and rs9322817 in HACE1 on TSH and thyroid hormone levels. Cohort $1=$ Busselton, Cohort $2=$ Depth, and Cohort $3=E F S O C H$.

\begin{tabular}{|c|c|c|c|c|c|c|}
\hline Cohorts & Gene & $\beta$ & $95 \% \mathrm{Cl}$ & $P$ value & $\mathbf{Q}$ & $\mathbf{p}(\mathbf{Q}) \geq$ \\
\hline \multicolumn{7}{|l|}{ TSH } \\
\hline $1,2,3$ & PDE8B & 0.205 & $(0.142,0.267)$ & $1.64 \times 10^{-10}$ & 0.093 & 0.955 \\
\hline 1,2 & DIO1 & -0.04 & $(-0.118,0.038)$ & 0.324 & 2.188 & 0.139 \\
\hline 1,2 & RAPGEF5 & -0.026 & $(-0.142,0.091)$ & 0.667 & 0.035 & 0.861 \\
\hline 1,2 & HACE1 & -0.004 & $(-0.087,0.079)$ & 0.928 & 0.562 & 0.453 \\
\hline \multicolumn{7}{|c|}{$(-0.001,0.015)$} \\
\hline $1,2,3$ & PDE8B & -0.039 & $(-0.102,0.023)$ & 0.218 & 0.106 & 0.948 \\
\hline 1,2 & DIO1 & 0.066 & $(-0.011,0.144)$ & 0.093 & 7.501 & 0.006 \\
\hline 1,2 & RAPGEF5 & -0.073 & $(-0.189,0.042)$ & 0.211 & 0.159 & 0.69 \\
\hline 1,2 & HACE1 & -0.003 & $(-0.086,0.079)$ & 0.936 & 0.251 & 0.616 \\
\hline \multicolumn{7}{|c|}{$(10.000,0.010)$} \\
\hline $1,2,3$ & PDE8B & -0.074 & $(-0.137,-0.010)$ & 0.023 & 0.205 & 0.902 \\
\hline 1,2 & DIO1 & -0.132 & $(-0.210,-0.054)$ & 0.001 & 0.014 & 0.907 \\
\hline 1,2 & RAPGEF5 & -0.041 & $(-0.158,0.076)$ & 0.491 & 0.304 & 0.582 \\
\hline 1,2 & HACE1 1 & -0.072 & $(-0.155,0.010)$ & 0.086 & 1.365 & 0.243 \\
\hline \multicolumn{7}{|l|}{$\mathrm{T}_{3}: \mathrm{T}_{4}$} \\
\hline $1,2,3$ & PDE8B & 0.027 & $(-0.036,0.089)$ & 0.407 & 0.469 & 0.791 \\
\hline 1,2 & DIO1 & 0.148 & $(0.071,0.226)$ & $9.2 \times 10^{-4}$ & 0.158 & 0.691 \\
\hline 1,2 & RAPGEF5 & -0.018 & $(-0.133,0.098)$ & 0.737 & 0.749 & 0.387 \\
\hline 1,2 & HACE1 & 0.055 & $(-0.027,0.138)$ & 0.189 & 2.617 & 0.106 \\
\hline
\end{tabular}

use in large epidemiological studies to examine the impact of small reductions in thyroid gland function on biological phenotypes and common diseases in the population. Such an approach can also then be used to explore the potential benefits of thyroid hormone supplementation in subjects with thyroid function in the lower parts of the reference range.

Second, our finding of reciprocal changes in TSH and free $\mathrm{T}_{4}$ with common genetic variation in PDE8B provides further support for the suggestion, arising from the data of Arnoud-Lopez et al. (10) that PDE8B plays a role in TSH signaling in the thyroid gland rather than operating at the level of central control of TSH secretion. This is entirely consistent with the predominant

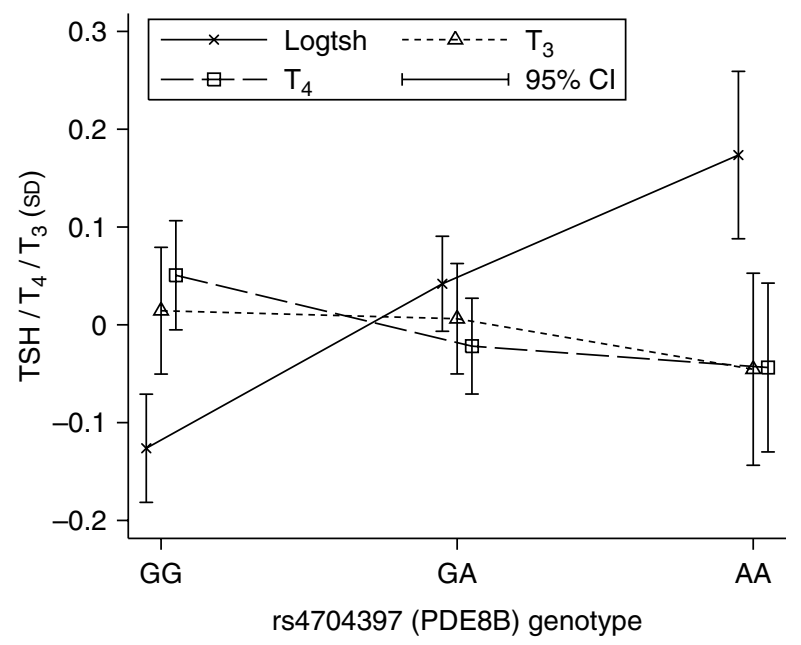

Figure 1 Standardized TSH, free $T_{3}$, and free $T_{4}$ levels by rs4704397 (PDE8B) genotype. expression of the PDE $8 B$ gene in the thyroid gland (14), with expression to a lesser extent in the brain (13).

The observation that the association with TSH is lost in subjects on thyroid hormone replacement is unlikely to be an issue of statistical power, as an association with TSH was seen in the DEPTH cohort (not on $\mathrm{T}_{4}$ ) that is smaller in number than WATTS (Table 3). This finding is also consistent with PDE $8 B$ having an effect at the level of the thyroid, as in these individuals thyroid responsiveness to TSH will play little or no role in determining thyroid hormone levels. In this context, it is interesting to note that individuals in the WATTS cohort have a higher free $\mathrm{T}_{4}(P \leq 0.001)$ and a lower free $\mathrm{T}_{3}$ $(P=0.04)$, despite having a similar TSH $(P=0.74)$ level to subjects in the Busselton cohort (general population) in keeping with previous reports (23). This trend persisted even when individuals with abnormal and suppressed TSH levels were removed from the WATTS cohorts; individuals in WATTS had a higher $\mathrm{T}_{4}$ $(P<0.001)$ and a lower free $\mathrm{T}_{3}(P=0.03)$ despite having similar TSH levels $(P=0.24)$. This observation emphasizes that although thyroid hormone replacement may restore an individual's TSH levels to within the 'normal population range', this may be outside an individual's genetically determined set point.

The rs4704397 SNP is present in intron 1 of the PDE 8B gene. However, it is possible that this SNP is not itself functional but linked to functional locus outside intron 1. Arnaud-Lopez et al. (10) have previously demonstrated that the rs4704397 SNP shows linkage disequilibrium with SNPs in neighboring regions. It is, however, unlikely to be involved in a coding region because sequence analysis of 20 subjects homozygous for the rare and 20 subjects for the common allele of rs4704397 did not demonstrate any coding variants 


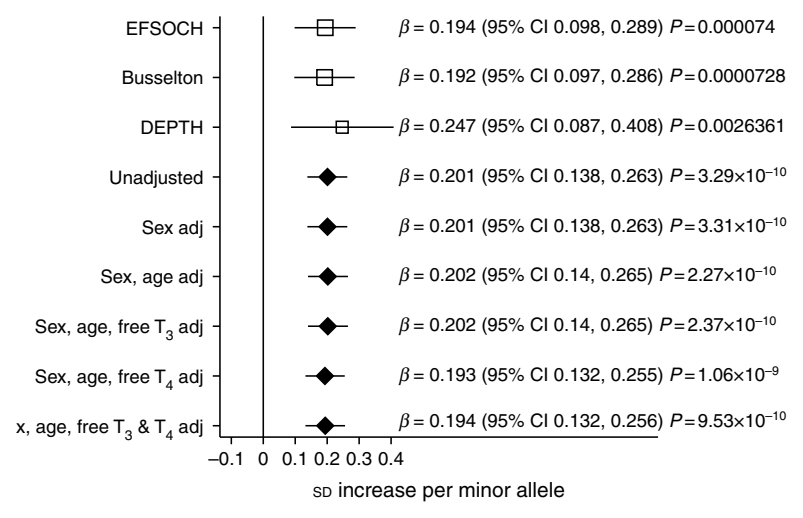

Figure 2 Association between $P D E 8 B$ and TSH levels by cohort and adjustment.

(10). We propose that the presence of additional minor A alleles results in increased phosphodiesterase activity of PDE8B and hence a reduced ability of the thyroid gland to generate free $\mathrm{T}_{4}$ (and free $\mathrm{T}_{3}$ ) when stimulated by TSH. This ultimately results in a reduction in free $\mathrm{T}_{4}$ and free $\mathrm{T}_{3}$ levels with a subsequently higher steady TSH level. As its mechanism of effect had been in the brain in altering the detection and subsequent set point of TSH, one would have expected higher TSH levels to be associated with higher thyroid hormone levels rather than a reciprocal relationship. Consistent with this, a recent report shows that variants in PDE $8 B$ associated with increased TSH levels segregate separately from a rare inactivating variant (H305P) in PDE8B (24).

The lack of association with free $\mathrm{T}_{3}$ levels in this study is likely to relate to the observation that TSH levels are more sensitive to free $\mathrm{T}_{4}$ than free $\mathrm{T}_{3}$ levels, both outside (25) and within (20) the normal range. Therefore, we suggest that the rs47044397 SNP probably influences free $\mathrm{T}_{3}$ levels in addition to free $\mathrm{T}_{4}$ (and indeed the trends in changes in free $\mathrm{T}_{3}$ were consistently in the same direction as free $\mathrm{T}_{4}$ and reciprocal to TSH - Tables 3 and 4), but the current meta-analysis was still underpowered to detect this. Adjusting for free $\mathrm{T}_{4}$ and free $\mathrm{T}_{3}$ levels only partially attenuates the effect of the PDE 8B SNP on TSH levels (Fig. 2). This implies that even given the log-linear relationship between TSH and free $\mathrm{T}_{4}$, the fall in $\mathrm{T}_{4}$ is insufficient to account for the whole rise in TSH. This discrepancy currently remains unexplained.

We were unable to confirm the association between the rs10499559 SNP in RAPGEF5 and the rs9322817 SNP in HACE1 with serum TSH levels. Genetic variation in rs932281 in HACE1 was evenly distributed in our cohorts, and our study was sufficiently powered to detect an effect of 0.10 s.D./allele. The initial identification of an association between this SNP and TSH may be due to a type 1 error or else its effect is only modest. By contrast, the mean allele frequency of rs10499559 in RAPGEF 5 is low, at 0.15 , in our cohorts and we were, therefore, only sufficiently powered to detect an association of 0.15 s.D./allele or higher. This SNP will require further replication studies in several large epidemiological cohorts with thyroid function available to fully assess its effect.

We were able to demonstrate the continuing association between genetic variation due to SNPs on TSH and thyroid hormone levels, and to our knowledge, this report is the first to provide evidence for this. The marked similarity in effect size per additional minor allele for both the rs4704397 SNP in PDE8B on TSH and free $\mathrm{T}_{4}$ and the rs2235544 SNP in DIO1 on free $\mathrm{T}_{4}$ over a 13-year period provides compelling evidence for the consistent associations of these SNPs on thyroid hormone parameters over time. Indeed, over this time interval, there was a mean increase in serum TSH of $0.31 \mu \mathrm{IU} / \mathrm{ml}$, and yet the relative genetic effect of these SNPs remained constant. This suggests that the genetic approach better reflects lifelong trends in TSH and thyroid hormone levels compared with individual serum values.

\section{Supplementary data}

This is linked to the online version of the paper at http://dx.doi.org/10. 1530/EJE-10-0938.

\section{Declaration of interest}

The authors declare that there is no conflict of interest that could be perceived as prejudicing the impartiality of the research reported.

\section{Funding}

This research did not receive any specific grant from any funding agency in the public, commercial or not-for-profit sector. N J Timpson is funded through the MRC Centre grant (MRC CAiTE Centre) G0600705.

\section{Acknowledgements}

We are extremely grateful to all the individuals and families who took part in these cohort studies and the research teams who collected the data. We also thank the Busselton Population Medical Research Foundation for approving the study and MRC CAiTE Bristol for statistical and epidemiological assistance.

\section{References}

1 Knudsen N, Laurberg P, Rasmussen LB, Bulow I, Perrild H, Ovesen L \& Jorgensen T. Small differences in thyroid function may be important for body mass index and the occurrence of obesity in the population. Journal of Clinical Endocrinology and Metabolism 200590 4019-4024. (doi:10.1210/jc.2004-2225)

2 Asvold BO, Vatten LJ, Nilsen TI \& Bjoro T. The association between TSH within the reference range and serum lipid concentrations in a population-based study. The HUNT Study. European Journal of Endocrinology 2007156 181-186. (doi:10.1530/eje.1.02333)

3 Asvold BO, Bjoro T, Nilsen TI \& Vatten LJ. Association between blood pressure and serum thyroid-stimulating hormone 
concentration within the reference range: a population-based study. Journal of Clinical Endocrinology and Metabolism 200792 841-845. (doi:10.1210/jc.2006-2208)

4 Alvarez-Pedrerol M, Ribas-Fito N, Torrent M, Julvez J, Ferrer C \& Sunyer J. TSH concentration within the normal range is associated with cognitive function and ADHD symptoms in healthy preschoolers. Clinical Endocrinology 200766 890-898. (doi:10. 1111/j.1365-2265.2007.02871.x)

5 Asvold BO, Bjoro T, Nilsen TI, Gunnell D \& Vatten LJ. Thyrotropin levels and risk of fatal coronary heart disease: the HUNT study. Archives of Internal Medicine 2008168 855-860. (doi:10.1001) archinte.168.8.855)

6 Smith GD. Reflections on the limitations to epidemiology. Journal of Clinical Epidemiology 200154 325-331. (doi:10. 1016/S0895-4356(00)00334-6)

7 Smith GD \& Ebrahim S. Mendelian randomisation: prospects, potentials and limitations. International Journal of Epidemiology 200433 30-42. (doi:10.1093/ije/dyh132)

8 Asvold BO, Bjoro T, Nilsen TI \& Vatten LJ. Tobacco smoking and thyroid function: a population-based study. Archives of Internal Medicine 2007167 1428-1432. (doi:10.1001/archinte.167.13. 1428)

9 Peeters RP, van Toor H, Klootwijk W, de Rijke YB, Kuiper GG, Uitterlinden AG \& Visser TJ. Polymorphisms in thyroid hormone pathway genes are associated with plasma TSH and iodothyronine levels in healthy subjects. Journal of Clinical Endocrinology and Metabolism 200388 2880-2888. (doi:10.1210/jc.2002021592)

10 Arnaud-Lopez L, Usala G, Ceresini G, Mitchell BD, Pilia MG, Piras MG, Sestu N, Maschio A, Busonero F, Albai G, Dei M, Lai S, Mulas A, Crisponi L, Tanaka T, Bandinelli S, Guralnik JM, Loi A, Balaci L, Sole G, Prinzis A, Mariotti S, Shuldiner AR, Cao A, Schlessinger D, Uda M, Abecasis GR, Nagaraja R, Sanna S \& Naitza S. Phosphodiesterase $8 \mathrm{~B}$ gene variants are associated with serum TSH levels and thyroid function. American Journal of Human Genetics 200882 1270-1280. (doi:10.1016/j.ajhg.2008. 04.019)

11 Panicker V, Cluett C, Shields B, Murray A, Parnell KS, Perry JR, Weedon MN, Singleton A, Hernandez D, Evans J, Durant C, Ferrucci L, Melzer D, Saravanan P, Visser TJ, Ceresini G, Hattersley AT, Vaidya B, Dayan CM \& Frayling TM. A common variation in deiodinase 1 gene DIO1 is associated with the relative levels of free thyroxine and triiodothyronine. Journal of Clinical Endocrinology and Metabolism 200893 3075-3081. (doi:10. 1210/jc.2008-0397)

12 Bender AT \& Beavo JA. Cyclic nucleotide phosphodiesterases: molecular regulation to clinical use. Pharmacological Reviews 2006 58 488-520. (doi:10.1124/pr.58.3.5)

13 Lakics V, Karran EH \& Boess FG. Quantitative comparison of phosphodiesterase mRNA distribution in human brain and peripheral tissues. Neuropharmacology 201059 367-374. (doi:10. 1016/j.neuropharm.2010.05.004)

14 Hayashi M, Matsushima K, Ohashi H, Tsunoda H, Murase S, Kawardada Y \& Tanaka T. Molecular cloning and characterization of human PDE8B, a novel thyroid-specific isoenzyme of $3^{\prime}, 5^{\prime}$-cyclic nucleotide phosphodiesterase. Biochemical and Biophysical Research Communications 1998250 751-756. (doi:10.1006/bbrc.1998. 9379)

15 Hayashi M, Shimada Y, Nishimura Y, Hama T \& Tanaka T. Genomic organization, chromosomal localization, and alternative splicing of the human phosphodiesterase $8 \mathrm{~B}$ gene. Biochemical and Biophysical Research Communications 2002297 1253-1258. (doi:10.1016/S0006-291X(02)02371-9)

16 Persani L, Borgato S, Lania A, Filopanti M, Mantovani G, Conti M \& Spada A. Relevant cAMP specific phosphodiesterase isoforms in human pituitary: effect of Gs (alpha) mutations. Journal of Clinical Endocrinology and Metabolism 200186 3795-3800. (doi:10. $1210 /$ jc. 86.8.3795)

17 Shields BM, Freathy RM, Knight BA, Hill A, Weedon MN, Frayling TM, Hattersley AT \& Vaidya B. Phosphodiesterase 8B gene polymorphism is associated with subclinical hypothyroidism in pregnancy. Journal of Clinical Endocrinology and Metabolism 2009 94 4608-4612. (doi:10.1210/jc.2009-1298)

18 Walsh JP, Bremner AP, Feddema P, Leedman PJ, Brown SJ \& O'Leary P. Thyrotropin and thyroid antibodies as predictors of hypothyroidism: a 13-year, longitudinal study of a communitybased cohort using current immunoassay techniques. Journal of Clinical Endocrinology and Metabolism 201095 1095-1104. (doi:10.1210/jc.2009-1977)

19 Hwang SJ, Yang Q, Meigs JB, Pearce EN \& Fox CS. A genome-wide association for kidney function and endocrine-related traits in the NHLBI's Framingham Heart Study. BMC Medical Genetics 20078 (Suppl 1) S10. (doi:10.1186/1471-2350-8-S1-S10)

20 Shields BM, Freathy RM, Knight BA, Hill A, Weedon MN, Frayling TM, Hattersley AT \& Vaidya B. Phosphodiesterase 8B gene polymorphism is associated with subclinical hypothyroidism in pregnancy. Journal of Clinical Endocrinology and Metabolism 2009 94 4608-4612. (doi:10.1210/jc.2009-1298)

21 O'Leary PC, Feddema PH, Michelangeli VP, Leedman PJ, Chew GT, Knuiman M, Kaye J \& Walsh JP. Investigations of thyroid hormones and antibodies based on a community health survey: the Busselton thyroid study. Clinical Endocrinology 2006 64 97-104. (doi:10.1111/j.1365-2265.2005.02424.x)

22 Saravanan P, Simmons DJ, Greenwood R, Peters TJ \& Dayan CM. Partial substitution of thyroxine $\left(\mathrm{T}_{4}\right)$ with tri-iodothyronine in patients on $\mathrm{T}_{4}$ replacement therapy: results of a large community-based randomized controlled trial. Journal of Clinical Endocrinology and Metabolism 200590 805-812. (doi:10.1210/ jc.2004-1672)

23 Saravanan P, Chau WF, Roberts N, Vedhara K, Greenwood R \& Dayan CM. Psychological well-being in patients on 'adequate' doses of L-thyroxine: results of a large, controlled communitybased questionnaire study. Clinical Endocrinology $2002 \mathbf{5 7}$ 577-585. (doi:10.1046/j.1365-2265.2002.01654.x)

24 Horvath A, Faucz F, Finkielstain GP, Nikita ME, Rothenbuhler A, Almeida M, Mericq V \& Stratakis CA. Haplotype analysis of the promoter region of phosphodiesterase type $8 \mathrm{~B}$ (PDE8B) in correlation with inactivating PDE8B mutation and the serum thyroid-stimulating hormone levels. Thyroid 201020 363-367. (doi:10.1089/thy.2009.0260)

25 Saberi M \& Utiger RD. Serum thyroid hormone and thyrotropin concentrations during thyroxine and triiodothyronine therapy. Journal of Clinical Endocrinology and Metabolism 197439 923-927. (doi:10.1210/jcem-39-5-923)

Received 7 December 2010

Accepted 11 February 2011 